Bol. Acad. peru. leng. 66. 2019 (273-277)

\title{
EL TALENTO DE «EL CONDE DE LEMOS»: VIDA Y OBRA DE ABRAHAM VALDELOMAR
}

\author{
Joyce Katheryn Gonzales Llerena \\ Colegio Mayor Secundario Presidente del Perú (COAR, Lima)
}

Fecha de recepción:

$18 / 10 / 2019$

Fecha de aceptación:

$30 / 11 / 2019$

Cuando se menciona escritor, genio multifacético, representante del Perú, ¿en quién se piensa? De inmediato, nuestro único pensamiento es Abraham Valdelomar. Él es un escritor poeta, ensayista, cronista y dramaturgo peruano reconocido a nivel mundial por sus conmovedoras obras que transmiten un sinfín de emociones, las cuales generan que todo quien lo lea se introduzca en la historia que se narra y se conmueva con ella. Algunas de sus obras son: «El vuelo de los cóndores», «El caballero Carmelo», «La ciudad de los tísicos», entre otros. Algunos de sus poemas más resaltantes son «Tristitia», «El hermano ausente en la cena de Pascua», "Corazón ponte en pie», entre otros. Desde mi punto de vista, Abraham Valdelomar fue fuertemente influenciado por el entorno en el que se desarrolló con sus costumbres y creencias, las cuales se reflejan en sus obras llenas de sentimientos como: tristeza, soledad e incomprensión. A continuación, presentaré tres argumentos que fundamentan mi postura.

https://doi.org/10.46744/bapl.201902.012 
En primer lugar, existió una fuerte influencia por las costumbres y creencias del Perú en Abraham Valdelomar, principalmente las de la Costa (Lea). Esto se evidencia en su obra Yerba Santa: «Recuerdo vagamente como se recuerda un sueño el día de Jueves Santo. Era el día del Señor de Luren, el patrón de mi pueblo. Durante muchas semanas antes empezaban a llegar a lea las ofrendas de todos los pueblos comarcanos; de los hacendados esplendidos de ese y de otros valles» (Valdelomar, 1917). Esta cita alude a las creencias religiosas que existen en el pueblo de Valdelomar, resaltando la muy popular costumbre de la celebración de «La Semana Santa»y, en especial, se menciona a un santo: el Señor de Luren, el cual es muy venerado en la zona de Lea. Además, se puede apreciar la gran nostalgia que siente al recordar vagamente las fiestas patronales del lugar en el que nació. También, se manifiesta otras costumbres y festividades del Perú en la célebre obra «El Caballero Carmelo»: «El pueblo está de fiesta. Banderas peruanas agitabanse sobre las casas por el día de la Patria, que allí sabían celebrar con una gran jugada de Gallos a la que solían ir con todos los hacendados y ricos hombres del valle» (Valdelomar, 1913). A partir de esta cita, se puede apreciar la manera como se celebraba las Fiestas Patrias y la muy popular costumbre de la época la pelea de gallos. Por ello, se puede decir que gracias a la influencia de las creencias y costumbres existentes del Perú se fortaleció el sentido de pertenencia y el patriotismo en las obras de Abraham Valdelomar.

En segundo lugar, Abraham Valdelomar recibió una gran influencia por parte de su familia. Esto se manifiesta en el poema «Tristitia». «Mi padre era callado y mi madre era triste /y la alegría nadie me la supo enseñar». Esta cita evidencia la lejanía de sus padres, además de la enorme confusión que sentía Abraham Valdelomar al ser incapaz de comprender el verdadero significado de la alegría. Asimismo, la familia de Valdelomar era de economía media, es decir, que alguien de aquella familia llegue a estudiar Letras y viajar por el mundo gracias a su talento era algo inimaginable. La carta (1913) de Abraham Valdelomar a su madre, publicada en El Diario Uno (2019), «Mi hotel cuesta once liras diarias. [...] El calor no están grande como dicen. Me quedaré aquí en Roma por lo menos ocho meses o diez. Pues solo saldré seis días, cuando reciba el dinero que he pedido para hacerme la ropa tendré que ir a 
https://doi.org/10.46744/bapl.201902.012

París». Lo que verdaderamente dice en esta cita es «No te preocupes». Valdelomar quiere ser capaz de proporcionarle calma y tranquilidad a su madre porque la ama demasiado como para preocuparla. La influencia de estos viajes y la nostalgia a la familia se evidencia en la obra «El Caballero Carmelo». Entonces, podemos decir que la actitud de los padres de Abraham Valdelomar influyó fuertemente en su vida y creó una mentalidad diferente de ver el mundo.

En tercer lugar, uno de los escritores que más influyó en la vida de Valdelomar fue José de la Riva Agüero. Esto se evidencia en la carta de Valdelomar a su madre (1913) publicada por El Diario Uno (2019) «No te imaginas la familia de Riva-Agüero, el ministro y José todo lo que han hecho conmigo. Parecía que yo fuera su hijo. No ha habido atención que no me hayan tenido». A partir de esta cita, podemos conocer las grandes medidas de cortesía y cuidado que tuvieron con él y que se sentía como un «hijo adoptado». Durante los años de 1914 a 1915, Valdelomar empezó a trabajar para José de la Riva Agüero secretario suyo.

Bajo su tutoría escribió La maríscala, una novela biográfica, de Francisca Zubiaga. Por ello, podemos decir que gracias a la tutela de José de la Riva Agüero se obtuvo un crecimiento personal y creativo, reflejado en sus obras.

En cuarto lugar, Abraham Valdelomar era capaz de transmitir un sinnúmero de emociones a través de sus escritos. Esto se evidencia en el poema «Corazón ponte en pie». «Olvida tu dolor, tu pena olvida, / cubre de flores, tu sutil guarida» (Valdelomar, 1916). Esta cita nos transmite sentimientos de pena, dolor, angustia y olvido. También, en «El hermano ausente en la cena de Pascua» proveniente del poemario Las voces múltiples. «La mesa antigua y holgada de nogal, / y sobre ella la misma blancura del mantel/y los cuadros de caza de anónimo pincel» (Valdelomar, 1916). Aquí se reflejan diversos sentimientos de nostalgia, tristeza y vacío. Por este motivo, se afirma que en cada uno de los escritos de Valdelomar se transmiten de manera espléndida los diferentes sentimientos y sensaciones que pueda tener el hombre. 
https://doi.org/10.46744/bapl.201902.012

A manera de conclusión, se puede afirmar que todas las vivencias que tuvo Abraham Valdelomar aportaron e influyeron en gran medida tanto en su desarrollo personal como en sus textos literarios y no literarios. Es decir, todo lo que aprendió, sufrió, disfrutó y vivió lo usó como un medio para inspirarse y crear las hermosas obras y conmovedores poemas, que lo llevarían a ser uno de los reconocidos y representativos del Perú. 
https://doi.org/10.46744/bapl.201902.012

\section{BIBLIOGRAFÍA}

Efemérides: 10 datos importantes que deberías saber sobre Abraham Valdelomar. Epistre Tv. Recuperado de https://www.epistre. net/2018/11/02/efemerides-10-datos-importantes- quedeberias-saber-sobre-abraham-valdelomar/.

Poemas de Abraham Valdelomar - Las mejores poesías de Abraham Valdelomar. (s. f.). Recuperado de https://www.buscapalabra. $\mathrm{com} /$ poetas.html?nombre $=$ Abraham $\% 20$ Valdelomar.

Diario UNO. (2019). Una carta de Valdelomar a su madre desde Roma. Recuperado de http;/diariouno.pe/una-carta-devaldelomar-a-su-madre- desde-roma/. 